\title{
Direct Synthesis of Carboranylpolystyrene and Their Applications for Oxidation Resistance of Graphene Oxides and Catalyst Support
}

\author{
Zhu Yinghuai, ${ }^{\mathrm{a}, *}$ Zhao Wenguang, ${ }^{\mathrm{a}}$ Narayan S Hosmane ${ }^{\mathrm{b}}$ \\ ${ }^{a}$ Institute of Chemical and Engineering Sciences (ICES), 1 Pesek Road, Jurong Island, \\ Singapore 627833 \\ Tel+6567963801, Fax+6563166184,_E-mail: zhu_yinghuai@ices.a-star.edu.sg \\ ${ }^{b}$ Department of Chemistry and Biochemistry, Northern Illinois University, DeKalb, \\ Illinois 60115-2862, USA,
}

\begin{abstract}
Radical polymerization reaction of carborane monomer closo-1-R-2-(4vinylbenzyl)-1,2- $\mathrm{C}_{2} \mathrm{~B}_{10} \mathrm{H}_{10}$ (R=Me (1), $\mathrm{Ph}$ (2)) produced carboranyl-functionalized polystyrenes, poly(1-R-2-(4-vinylbenzyl)-1,2-closo- $\left.\mathrm{C}_{2} \mathrm{~B}_{10} \mathrm{H}_{10}\right)(\mathrm{R}=\mathrm{Me}(3), \mathrm{Ph}(4))$, in a yield of $56.3 \%$ and $85.0 \%$, respectively. The polymers 3 and 4 were used to coat graphene oxides $(\mathrm{GO})$ and the resulting products exhibited high oxidation resistance property when compared with pristine GO. Polymer 3 was also used to stabilize palladium nanoparticles (Pd-NPs) to form catalyst composite Pd-NPs/3. Composite Pd$\mathrm{NPs} / \mathbf{3}$ was found to be efficient catalyst for selective oxidation of glycerol. All new compounds were fully characterized.
\end{abstract}

Keywords: Carborane; Functional polystyrene; Pd (0) nanoparticles; Graphene oxides; Oxidation resistance; Selective oxidation. 


\section{Introduction}

Polymers incorporating carborane units exhibit unique properties due to inherent chemical inertness, high hydrophobicity, electron deficient, thermal and radiation stability of carborane cages [1-17]. For example, silicone polymers with closo-carborane, $\mathrm{C}_{2} \mathrm{~B}_{10} \mathrm{H}_{12}$, incorporated in its backbone show promising oxidative stability at high temperatures [1-3]. This type of polymers could find many new applications, other than oxidation resistance reagents, in the near future including those in electrochromic device [12], neutron detector [14] and boron neutron capture therapy [18]. Various methods such as Sonogashira-Hagihara polycondensation [5,8], Stille coupling reaction [11,12] and click-grafting [19], have been used to synthesize carborane-containing polymers. Due to high oxidative and thermal stability of closo-carborane cage, the closo-carborane appended polystyrenes are expected to show improved thermal and oxidative stability when compared with pristine polystyrenes. Therefore, such polymers have good potential as catalyst supports for oxidative coupling reactions. However, in click-grafting method in which carborane cages were attached to polystyrene chain by an azide-alkyne click cycloaddition reactions, high toxic $\mathrm{Cu}^{\mathrm{I}}$-based catalyst was used [19, 20]. Similar to other click reactions, the inherent drawbacks such as contamination of $\mathrm{Cu}^{\mathrm{I}}$ catalyst species even after completion of the reaction may limit their further applications such as in drug delivery. Removal of remaining metal species from polymer products is particularly challenging because they could be trapped in polymers folds. In this work, carboraneappended polystyrenes, poly(1-R-2-(4-vinylbenzyl)-1,2-closo- $\left.\mathrm{C}_{2} \mathrm{~B}_{10} \mathrm{H}_{10}\right)(\mathrm{R}=\mathrm{Me}(3), \mathrm{Ph}$ (4)), were synthesized by direct radical polymerization reactions.

On the other hand, graphene oxide (GO) has been known for more than one and a half century [21], it has many intriguing properties and potential applications [22]. However, GO possesses thermal and oxidative instability and some of the carbon atoms are oxidized to carbonaceous gases at elevated temperature $\left(\sim 210^{\circ} \mathrm{C}\right)$ [21]. Sandoval, et al reported that nitrogen-doped grephene oxide exhibits increased thermal stability against oxidation by air [22]. Relatively critical conditions such as high temperature $\left(500^{\circ} \mathrm{C}\right.$ and 
$\left.800^{\circ} \mathrm{C}\right)$ and corrosive gas $\left(\mathrm{NH}_{3}\right)$ were used [22] in the process. Since closo-carboraneappended polymers have the potential resistance toward oxidation at high temperatures, polymers 3 and $\mathbf{4}$ were used to improve stability of GOs. In addition to its application in oxidation resistance, polymer $\mathbf{3}$ was also used as catalyst support. Palladium nanoparticles were supported on polymer $\mathbf{3}$ to form a catalyst composite. The palladium-based catalysts play important roles in many organic transformations including $\mathrm{C}-\mathrm{C}$ coupling reactions that have been well-investigated and documented [23-27].

We have been using Pd catalysts in biomass conversions to value added chemicals via selective oxidation reactions [28] and demonstrated their promising catalytic activity. Dihydroxyacetone (DHA) is being the most popularly used ingredient in current sunless tanners approved by the US Food and Drug Administration (FDA) [29]. Commercially available, high-priced DHA is generally produced in an atom-inefficient fermentation process [29]. The inherent drawbacks make the existing technology not efficient from the ecological, energetic, economical, and chemical standpoint. Heterogeneous catalysts possess obvious advantages in product isolation and, therefore, received growing interest for their use [30]. It has been known for a long time that supported platinum catalysts can be used for catalytic alcohol oxidation to aldehydes or ketones in aqueous media. Nonetheless, the deactivation of these catalysts in such reactions is a serious problem [31]. The fact that carboranyl-appended polystyrene with high oxidation stability are prepared in our laboratory, we report herein the synthesis and application of catalyst composite for selective oxidation of biomass-based glycerol to 1,3-dihydroxyacetone.

\section{Results and discussion}

Carborane-appended styrene monomers $\mathbf{1}$ and $\mathbf{2}$ were prepared by substitution reactions between in situ generated lithium salts of [closo-1-R-1,2- $\left.\mathrm{C}_{2} \mathrm{~B}_{10} \mathrm{H}_{10}\right]^{-}$anion and 4vinylbenzyl chloride in $71.2 \%$ and $81.7 \%$ yields, respectively (Scheme 1). The ${ }^{1} \mathrm{H},{ }^{13} \mathrm{C}$, and ${ }^{11} \mathrm{~B}$ NMR spectra are similar to those found for other related structures. In ${ }^{13} \mathrm{C}$ NMR spectra, unsaturated $\mathrm{C}=\mathrm{C}$ bonds show double peaks in the region of 114.31-114.56 ppm. In ${ }^{11} \mathrm{~B}$ NMR spectra, $\mathbf{1}$ and $\mathbf{2}$ gave different resonance patterns. Compound $\mathbf{1}$ shows a 
1:1:2:2:4 splitting pattern, while 2 exhibits a 2:4:4 resonance peaks. This could be due to the presence of different substituted moieties, methyl verses phenyl, on carborane cages. In the IR spectra, strong absorptions at $v=2562 \mathrm{~cm}^{-1}$ and $2565 \mathrm{~cm}^{-1}$ are attributed to $v_{\mathrm{BH}}$ as shown in Figure 1. Direct polymerization of carboranyl styrene monomers were carried out in toluene media. In order to avoid the risk of violent decomposition during the polymerization, benzoyl peroxide was not used, instead the safer azobisisobutyronitrile (AIBN) was chosen to be an initiator. Polymers $\mathbf{3}$ and $\mathbf{4}$, poly(closo-1-R-2-(4-vinylbenzyl)-1,2- $\left.\mathrm{C}_{2} \mathrm{~B}_{10} \mathrm{H}_{10}\right)(\mathrm{R}=\mathrm{Me}(3), \mathrm{Ph}(4))$ were obtained with $\mathrm{Mw}$ of 5795 (DPI = 2.37) and 3029 (DPI = 1.79), respectively. The lower Mw of 4 could be due to steric effect of phenyl substituent on the cage carbon. The ${ }^{1} \mathrm{H},{ }^{13} \mathrm{C}$, and ${ }^{11} \mathrm{~B}$ NMR spectra appear normal as broad peaks with the disappearance of the vinyl $\left(\mathrm{CH}=\mathrm{CH}_{2}\right)$ groups when compared to those of the corresponding monomers, thus confirming the success of radical polymerizations. As found for monomers, strong absorptions around $v=2560 \mathrm{~cm}^{-1}$ that are assigned as $\mathrm{BH}$ stretching mode of vibrations $\left(v_{\mathrm{BH}}\right)$ were also observed in the FT-IR spectra of the resulting polymers.

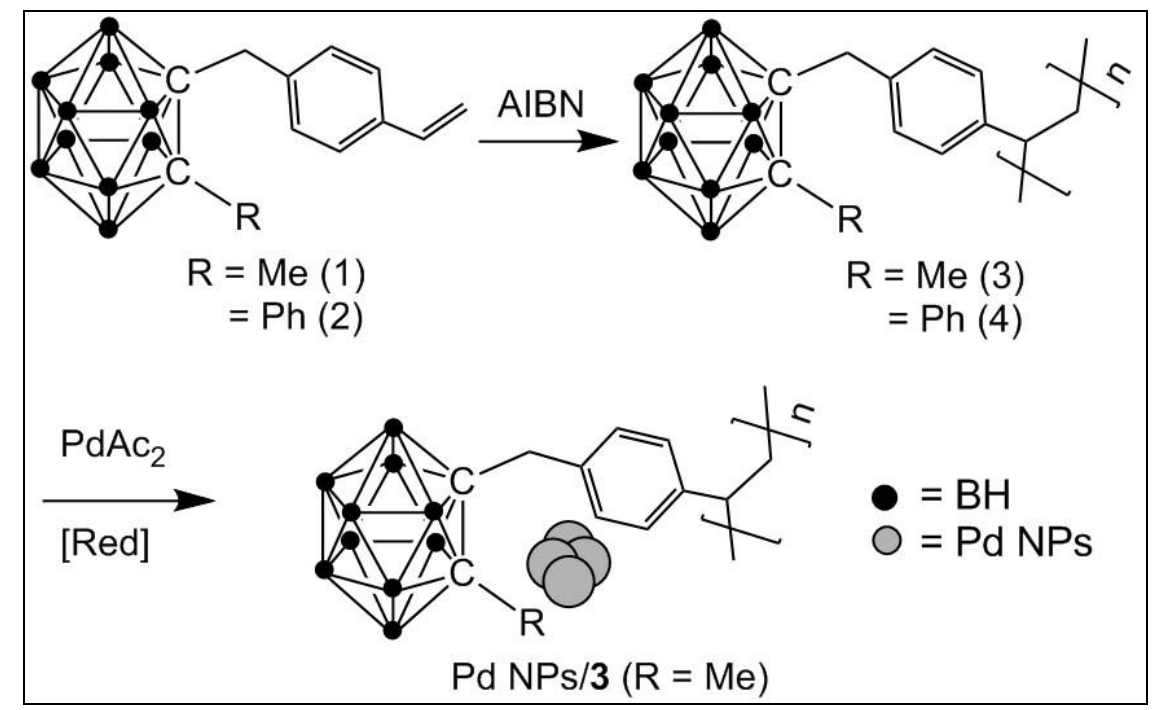

Scheme 1 Syntheses of carboranylpolystyrene and Pd NPs supported composites. 


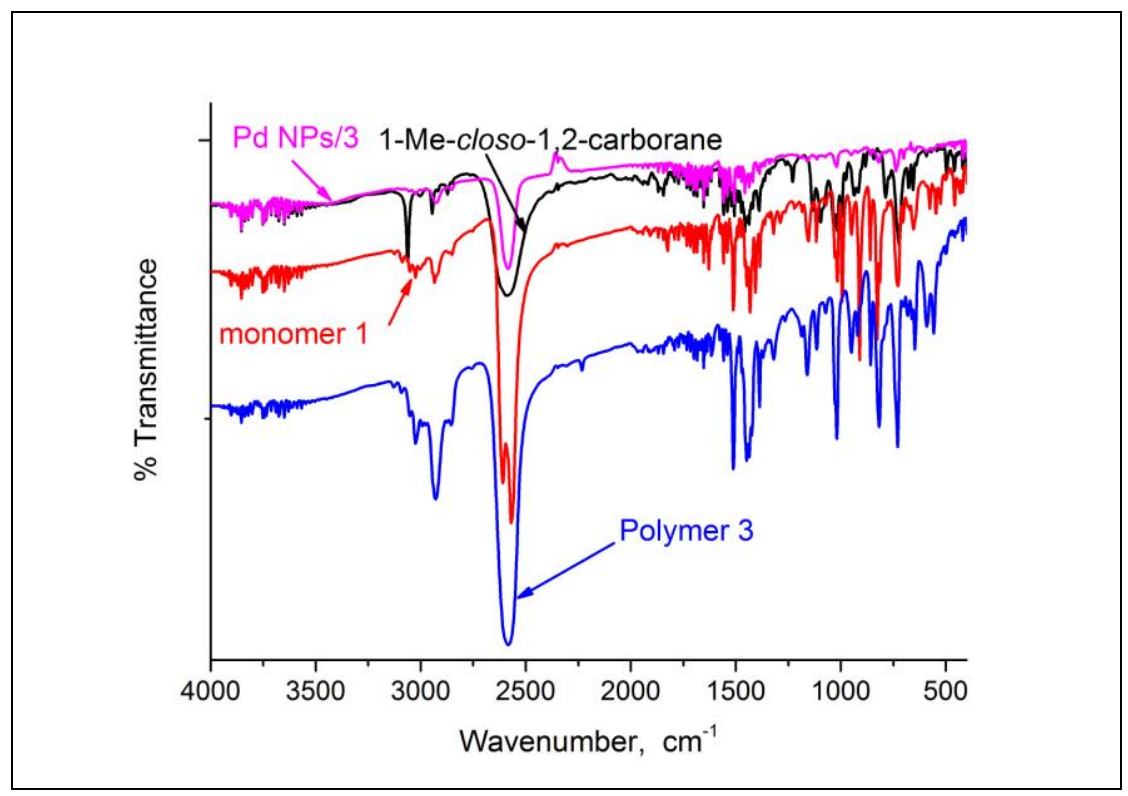

Figure 1 FT-IR spectra of 1-Me-1,2-closo- $\mathrm{C}_{2} \mathrm{~B}_{10} \mathrm{H}_{11}, \mathbf{1}, \mathbf{3}$, and Pd NPs on 3.

The GOs were coated with carboranylpolystyrene polymers by dipping into their corresponding solutions. The resulting composites were heated to $1000{ }^{\circ} \mathrm{C}$ in a stream of nitrogen gas to produce ceramic-coated GOs-based thermosets. In TGA analysis, the thermosets showed improved thermal stability at high temperatures in airflow of 100 $\mathrm{mL} / \mathrm{min}$ as shown in Figure 2. On the other hand, the pristine GOs burned completely at $221{ }^{\circ} \mathrm{C}$ in airflow $(100 \mathrm{ml} / \mathrm{min})$. Under the same conditions, thermosets $3-\mathrm{GOs}$ and 4GOs started losing weights at $536{ }^{\circ} \mathrm{C}$ and $552{ }^{\circ} \mathrm{C}$, respectively, and thus showed significantly improved thermal and oxidative stability at $>300{ }^{\circ} \mathrm{C}$ in airflow. The combustion temperature is comparable to that of previously reported nitrogen-doped GOs $\left(520{ }^{\circ} \mathrm{C}\right.$ and $\left.579{ }^{\circ} \mathrm{C}\right)$, that were prepared under the harsh conditions of high temperatures (500-800 ${ }^{\circ} \mathrm{C}$ ) in corrosive ammonia [22]. In comparison, the GOs were also coated with commercially available polystyrene (Mw 35000, Sigma-Aldrich) and then subjected to TGA analysis (Figure 2). It was observed that the polystyrene-GOs composite started to lose weight at a temperature of $210^{\circ} \mathrm{C}$ in air. The maximum weight loss temperature is around $292{ }^{\circ} \mathrm{C}$. This temperature is significantly lower than that for carboranylpolystyrene-GOs composite. This results suggested that the attachment of carborane cages is crucial to improve the thermal and oxidative stability of GOs. 
Although the real reason is not yet clear, it was proposed that a thermally stable film was generated in situ from the carborane cages in the continuous heating process, and the resulting film protected GOs to improve their stability.

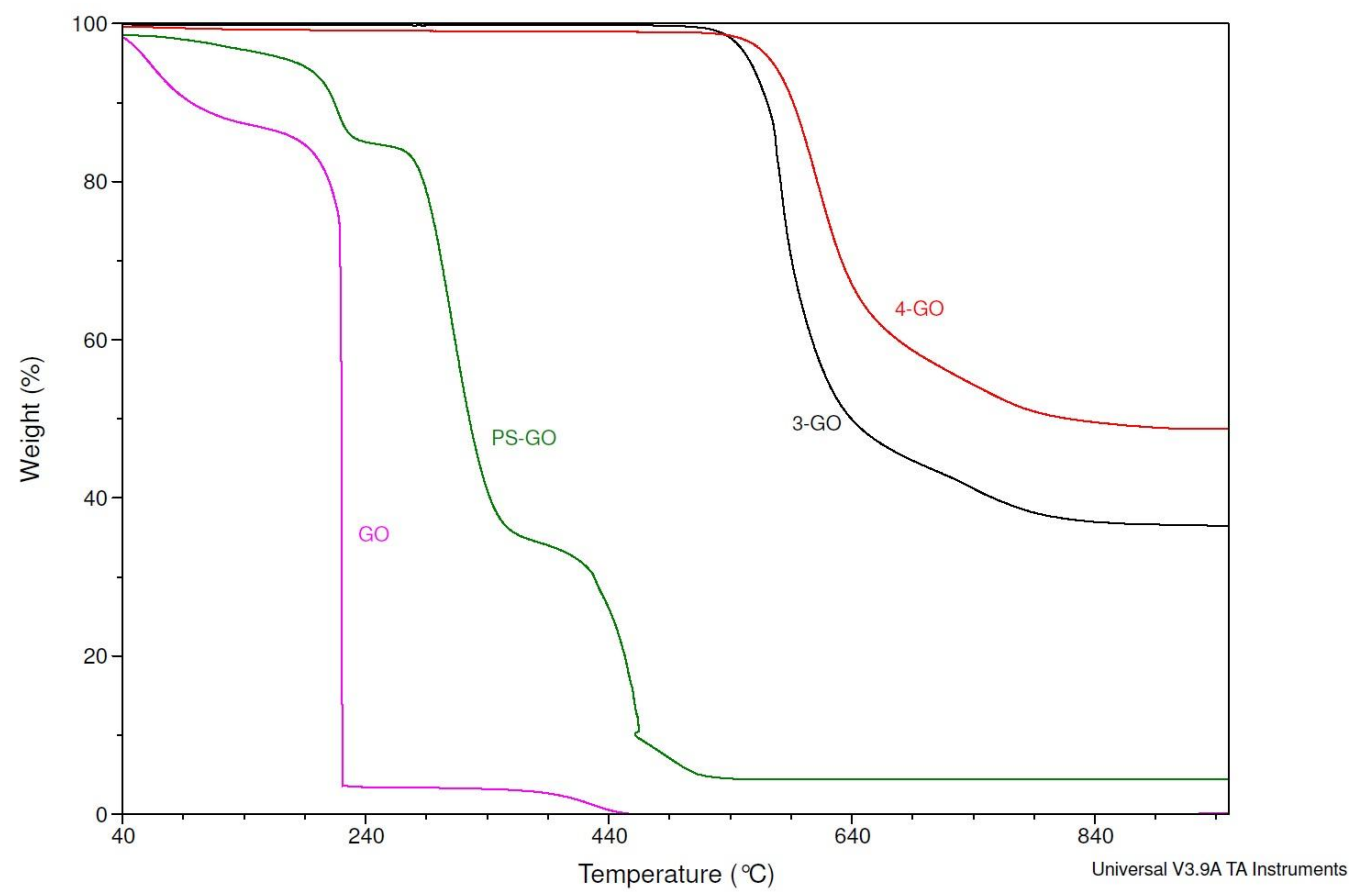

Figure 2. TGA spectra of GO, Poly(methylcarbonylstyrene) (3)-GO,

Poly(methylcarbonylstyrene) (4)-GO and polystyrene-GO by burning in air.

Palladium (0) nanoparticles were prepared in situ by reducing palladium acetate with phenyl boronic acid and then supported on carborane-appended polystyrene $\mathbf{3}$ following the literature procedure [32]. The synthesized catalyst composite was analyzed using ICP, XPS as well as TEM to identify the loading amount, chemical oxidation state and particle size of the supported palladium species. As shown in TEM images (Figure 3), the produced Pd particles are small crystalline in nanometric size with an average size of around $4.7 \mathrm{~nm}$ and a relatively narrow size distribution (Figure 4 (A), determined from the measurement of $\sim 100$ particles). The uniform nanoparticles were well dispersed on the polymer support. The samples for XPS analysis were prepared in a glove-box as described elsewhere [33-37]. The XPS spectrum of the samples (see Figure 4 (B)) showed typical $\mathrm{Pd}(0)$ absorptions at 335.68 and $341.08 \mathrm{eV}$ for $3 \mathrm{~d}_{5 / 2}$ and $3 \mathrm{~d}_{3 / 2}$, 
respectively, with $\Delta=5.4 \mathrm{eV}$, that is consistent with the literature values for $\mathrm{Pd}(0)$ [3337].

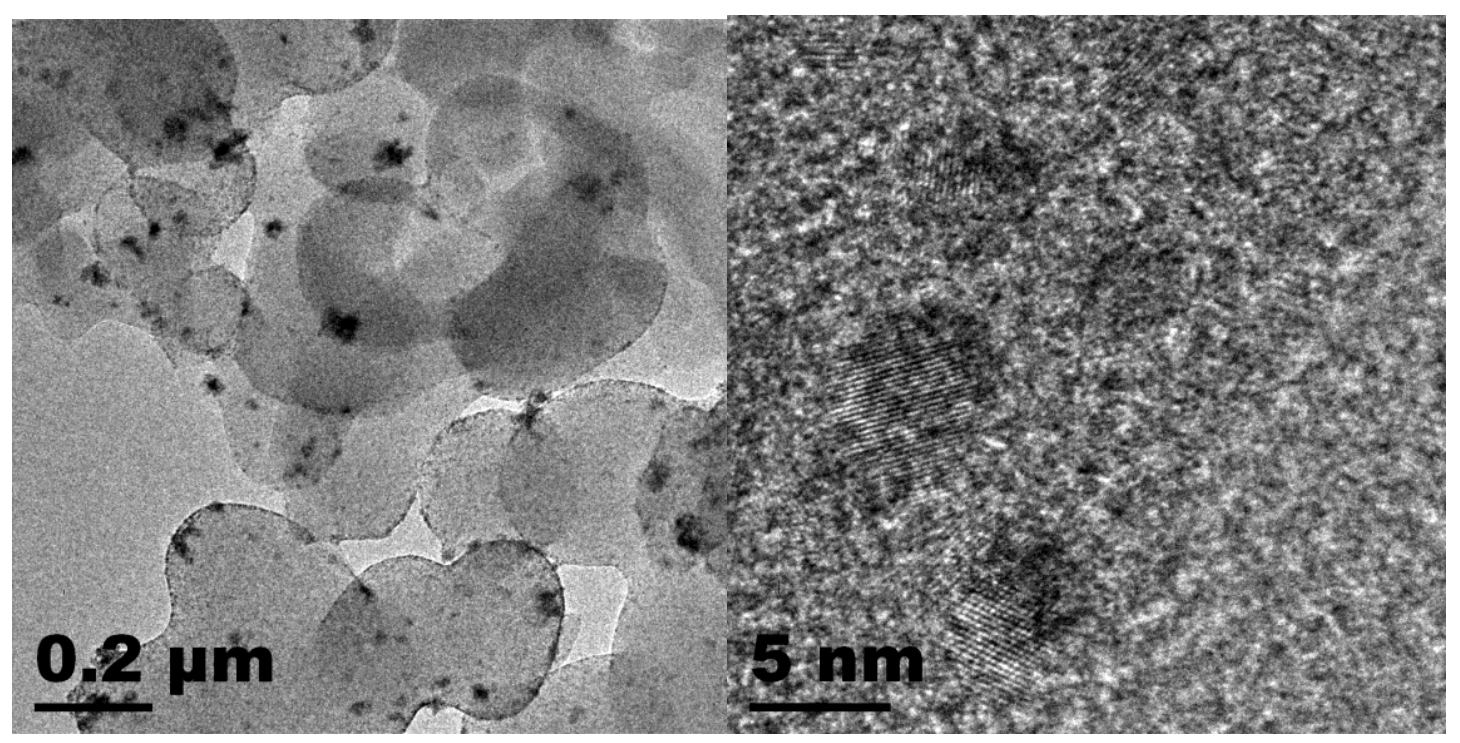

Figure 3 TEM images of nano-Pd/3.

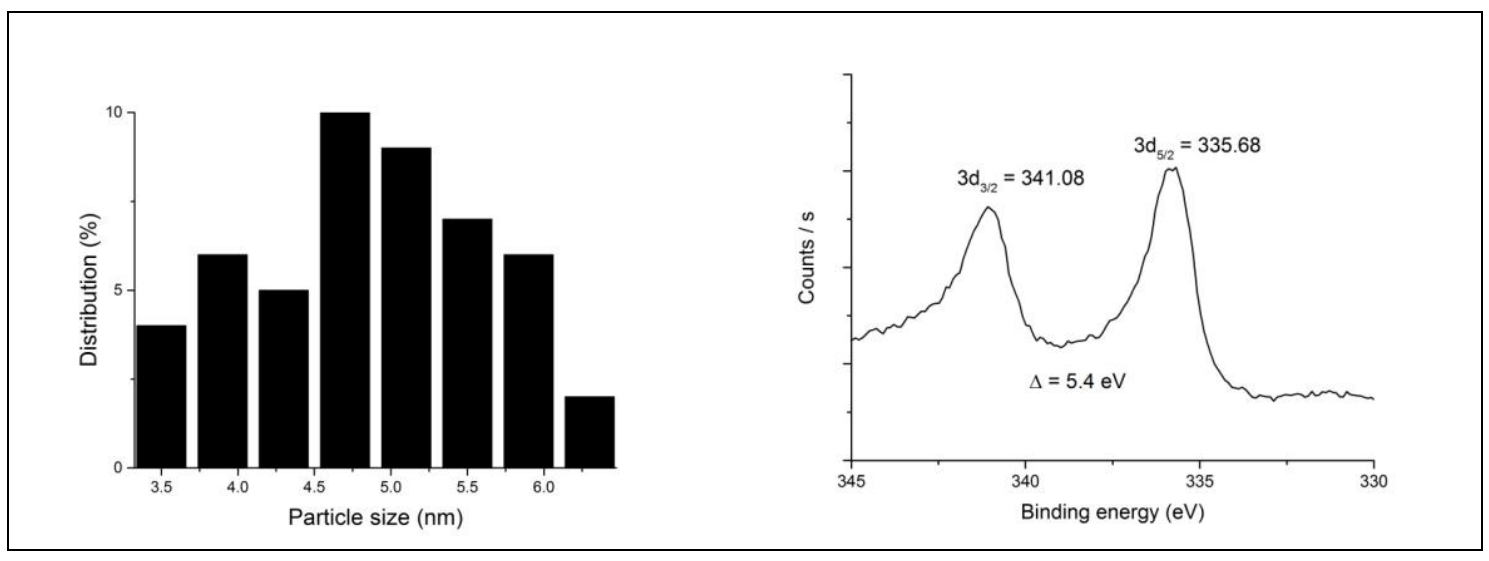

(A)

(B)

Figure 4 Size histogram (A) and XPS spectrum (B) of supported Pd nanoparticles.

The prepared composite made of palladium nanoparticles supported on polymer $\mathbf{3}$ were examined as catalysts in the selective oxidation reaction of glycerol to produce 1,3dihydroxy acetone (DHA). Trichloroisocyanuric acid (TCCA) has been recognized as one of the sustainable oxidants. TCCA is readily available, low toxic and less corrosive, 
and thus it has been widely utilized in organic reactions other than its use in the water purification and sanitization [38, 39]. TCCA was also used as oxidant for the conversion process. Under these reaction conditions, DHA was obtained in 52\% yield that is slightly higher than that for carbon supported Pt-Bi catalyst which gave a $44.8 \%$ yield [40]. The $\mathrm{Pt}-\mathrm{Bi}$ catalyst was reported to afford higher activity than others such as $\mathrm{Pd} /$ carbon and $\mathrm{Pd} / \mathrm{TiO}_{2}[40,41]$. For comparison, polystyrene supported $\mathrm{Pd}$ catalyst was also prepared and examined for the glycerol oxidation reaction. As shown in Figure 5, Pd nanoparticles in the catalyst of nano-Pd/polystyrene aggregate heavily. A DHA yield of $27 \%$ was obtained with the catalyst under similar conditions. The low activity could be due to catalyst aggregation.

It should be pointed out that the support could be separated conveniently by filtration and reused at least 3 times with the yield of $49 \%, 47 \%$ and $50 \%$ for the glycerol oxidation reaction under the same conditions. To investigate the leached $\mathrm{Pd}$, the samples of the filtrate plus washings obtained from above standard reactions were subjected to ICP analysis that showed the concentrations of Pd were to be less than $5.0 \mathrm{ppm}$. In addition, the standard reaction was conducted with the recovered filtrate, but no product could be isolated. The results suggested that the supported Pd NPs, rather than the leached Pds, provided the active centers. The detailed mechanistic study of the reaction is currently underway in our laboratories.

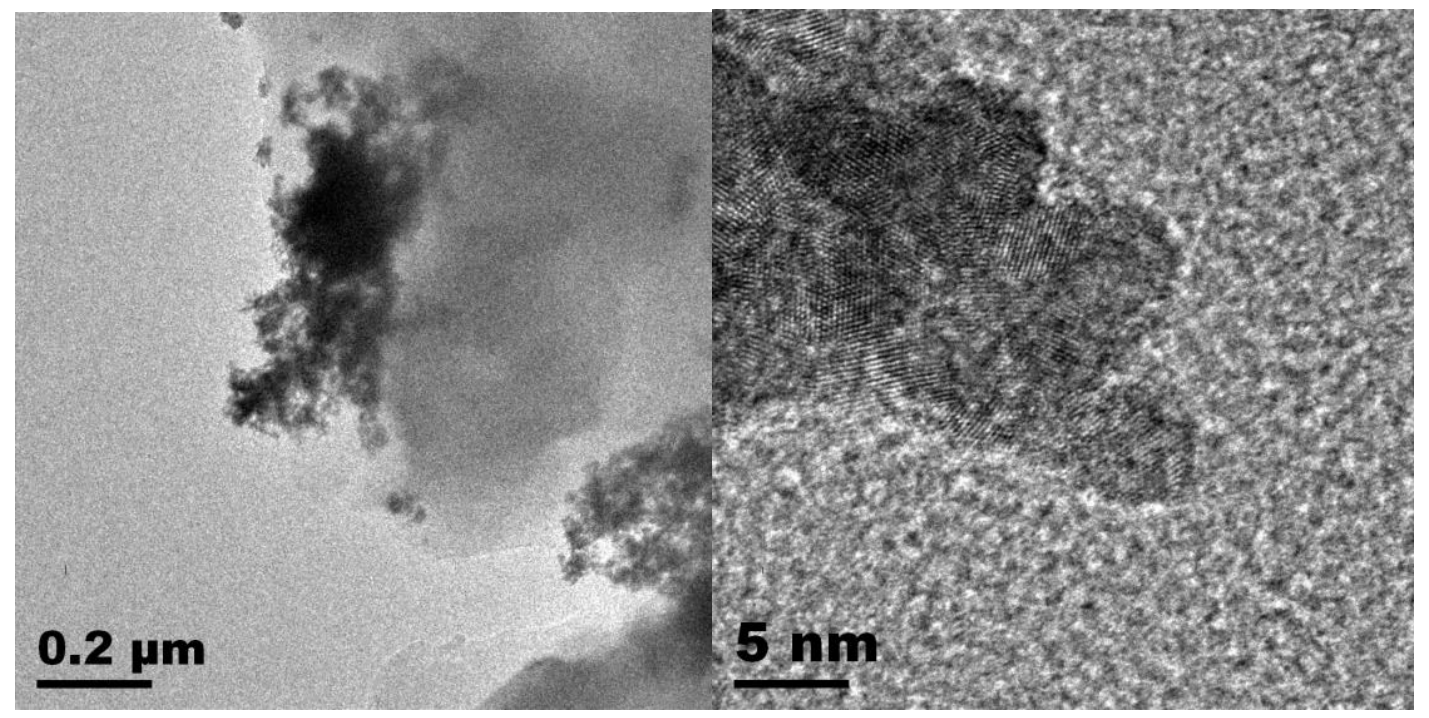


Figure 5 TEM images of nano-Pd/polystyrene.

\section{Conclusions}

Carborane-appended styrene monomers were synthesized in high yields. The monomers were able to conduct radical polymerization reactions in the presence of AIBN initiator to produce carborane-appended polystyrenes. Carboranylpolystyrene-coated graphene oxides showed higher combustion temperature when compared to that with pristine GOs. Both the thermal and oxidation stability of the GOs have been improved significantly. In addition, it has been concluded that the well-dispersed, polymer-supported palladium nanoparticle composite was found to be efficient catalyst for the glycerol oxidation reaction. It is expected that our protecting methodology and prototype catalyst will find broader applications in both academia and industry.

\section{Experimental}

All synthetic procedures and operations were carried out in an argon atmosphere using standard Schlenk techniques or a glove box. Organic solvents such as toluene and hexane were dried using standard procedures and distilled under argon before use [42]. 1-Mecloso-1,2- $\mathrm{C}_{2} \mathrm{~B}_{10} \mathrm{H}_{11}$ and 1-Ph-closo-1,2- $\mathrm{C}_{2} \mathrm{~B}_{10} \mathrm{H}_{11}$ were obtained from KatChem s. r. o., Czech Republic. Palladium acetate, sodium borohydride and other chemicals were

purchased from Sigma-Aldrich. The ${ }^{1} \mathrm{H},{ }^{13} \mathrm{C}$ and ${ }^{11} \mathrm{~B}$ NMR spectra were recorded on a Bruker Fourier-Transform multinuclear NMR spectrometer at 400, 100.6 and $128.4 \mathrm{MHz}$, relative to external $\mathrm{Me}_{4} \mathrm{Si}$ (TMS) and $\mathrm{BF}_{3} \cdot \mathrm{OEt}_{2}$ standards. Infrared (IR) spectra were measured using a BIO-RAD spectrophotometer with $\mathrm{KBr}$ pellets technique and presented in the sequence of signal strength as strong (s), medium (m) and weak (w), and peak pattern as single (s), multiple (m) and broad (br). The mass spectral (MS-ESI) analyses were carried out on a Thermo Finnigan MAT XP95 analyzer using ESI model. Gel permeation chromatography (GPC) was performed in DMF $(0.8 \mathrm{ml} / \mathrm{min})$ on an Agilent 1200 Chromatograph equipped with an RI detector. A combination of 2 x PLgel $5 \mu \mathrm{m}$ 
Mixed-columns was used. The molecular weights were calibrated with commercial polystyrene standards. Thermogravimetric analysis (TGA) was performed with a TA Instruments Q2960 from 35 to $1000{ }^{\circ} \mathrm{C}$ at a heating rate of $10^{\circ} \mathrm{C} / \mathrm{min}$ under a nitrogen or air flow (100 ml/min). Transmission electron microscopy (TEM) measurements were carried out on a JEOL Tecnai-G ${ }^{2}$, FEI analyzer at $200 \mathrm{Kv}$. Inductively coupled plasma (ICP) analysis was determined using a VISTA-MPX, CCD Simultaneous ICP-OES analyzer. X-Ray photoelectron spectrometer (XPS) was performed with an ESCALAB 250 analyzer.

4.1 Synthesis of closo-1-Me-2-(4-vinylbenzyl)-1,2- $C_{2} B_{10} H_{10}(\mathbf{1})$.

A modified literature method was used to prepare compounds 1 and 2 [43]. In brief, a solution of $3.17 \mathrm{~g}(20.0 \mathrm{mmol})$ of $1-\mathrm{Me}-1,2-\mathrm{C}_{2} \mathrm{~B}_{10} \mathrm{H}_{11}$ dissolved in $100 \mathrm{~mL}$ diethyl ether was cooled to $-78{ }^{\circ} \mathrm{C}$ and $14.00 \mathrm{~mL}(22.4 \mathrm{mmol})$ of $n$-BuLi (1.6 M in n-hexane) was added with syringe. After stirring for half an hour at $-78{ }^{\circ} \mathrm{C}$, the mixture was allowed to warm to room temperature with constant stirring for 6 hours, followed by the addition of $3.40 \mathrm{~mL}(26.8 \mathrm{mmol})$ of 4 -vinylbenzyl chloride with a syringe at $0{ }^{\circ} \mathrm{C}$. The reaction was then allowed to continue at room temperature for another 15 hours followed by refluxing for 4 hours before cooling to room temperature. The hydrolysis of the resulting mixture was carried out at room temperature with $10 \mathrm{~mL}$ of water. The organic phase was isolated using a separating funnel, and the aqueous phase was extracted with 2 x $40 \mathrm{~mL}$ diethyl ether. The combined organic phase was dried with $\mathrm{MgSO}_{4}$ and filtered, the filtrate was dried under reduced pressure and the resulting residue was recrystallized with $n$-pentane to obtain 3.91g waxy solid (1) in $71.2 \%$ yield. MS (ESI) for $\mathrm{C}_{12} \mathrm{H}_{22} \mathrm{~B}_{10}: \mathrm{m} / \mathrm{z}=272.18$ $[\mathrm{M}-2 \mathrm{H}]^{+} .{ }^{1} \mathrm{H}$ NMR $\left(\mathrm{CDCl}_{3}, \mathrm{ppm}\right), \delta=7.34-7.06\left(\mathrm{~m}, 4 \mathrm{H}, \mathrm{C}_{6} \underline{\mathrm{H}}_{4}\right), 6.64\left(\mathrm{~m}, 1 \mathrm{H}, \mathrm{C} \underline{\mathrm{H}}=\mathrm{CH}_{2}\right)$, 5.68-5.23 (q, $\left.2 \mathrm{H}, \mathrm{CH}=\underline{\mathrm{C}}_{2}\right), 3.40\left(\mathrm{~s}, 2 \mathrm{H}, \underline{\mathrm{C}}_{2}-\mathrm{C}_{6} \mathrm{H}_{4}\right), 2.72-1.14$ (m, br, $13 \mathrm{H}, \mathrm{C}_{\text {cage }}-\underline{\mathrm{C}}_{3} \underline{3}_{3}$, $\left.\mathrm{B}_{10} \underline{\mathrm{H}}_{10}\right) .{ }^{13} \mathrm{C} \mathrm{NMR}\left(\mathrm{CDCl}_{3}, \mathrm{ppm}\right), \delta=137.34,136.11,134.44,130.51$ and $126.38\left(\underline{\mathrm{C}}_{6} \mathrm{H}_{5}\right)$, 114.56 and $114.53\left(\underline{\mathrm{CH}}=\underline{\mathrm{CH}}_{2}\right), 77.51$ and $74.80\left(\underline{\mathrm{C}}_{\text {cage }}\right), 40.95\left(\underline{\mathrm{CH}}_{2}-\mathrm{C}_{6} \mathrm{H}_{4}\right), 23.70\left(\mathrm{C}_{\text {cage }^{-}}\right.$ $\left.\underline{\mathrm{CH}}_{3}\right) .{ }^{11} \mathrm{~B} \mathrm{NMR}\left(\mathrm{CDCl}_{3}, \mathrm{ppm}\right), \delta=-4.19\left(1 \mathrm{~B},{ }^{1} \mathrm{~J}_{\mathrm{BH}}=195 \mathrm{~Hz}\right),-5.55\left(1 \mathrm{~B},{ }^{1} \mathrm{~J}_{\mathrm{BH}}=153 \mathrm{~Hz}\right),-$ $8.67\left(2 \mathrm{~B},{ }^{1} \mathrm{~J}_{\mathrm{BH}}=80 \mathrm{~Hz}\right),-9.36\left(2 \mathrm{~B},{ }^{1} \mathrm{~J}_{\mathrm{BH}}=98 \mathrm{~Hz}\right),-10.33\left(4 \mathrm{~B},{ }^{1} \mathrm{~J}_{\mathrm{BH}}=152 \mathrm{~Hz}\right) . \mathrm{IR}(\mathrm{KBr}$ pellet, $\left.\mathrm{cm}^{-1}\right), 2930(\mathrm{~m}, \mathrm{~s}), 2608(\mathrm{vs}, \mathrm{s}), 2565(\mathrm{vs}, \mathrm{s}), 1825(\mathrm{w}, \mathrm{s}), 1629(\mathrm{~m}, \mathrm{~s}), 1510(\mathrm{~s}, \mathrm{~s})$, 
1432 (s, s), 1288(w, s), 1154 (w, s), 1113(m, s), 1017(s, s), 991(s, s), 947(w, s), 910(s, s), 851(m, s), 822(s, s), 728(s, s), 654(w, s), 549(s s), 455(w, s).

4.2 Synthesis of closo-1-Ph-2-(4-vinylbenzyl)-1,2- $C_{2} B_{10} H_{10}(2)$.

Compound 2 was prepared using the same procedure as described above in 4.1. A 5.50g (81.7\% yield) of 2 was obtained from $4.43 \mathrm{~g}(20.0 \mathrm{mmol})$ of $1-\mathrm{Ph}-1,2-\mathrm{C}_{2} \mathrm{~B}_{10} \mathrm{H}_{11}, 14.00$ $\mathrm{mL}(22.4 \mathrm{mmol})$ of $n$-BuLi $(1.6 \mathrm{M}$ in $\mathrm{n}$-hexane $)$ and $3.40 \mathrm{~mL}(26.8 \mathrm{mmol})$ of 4 vinylbenzyl chloride. $\mathrm{MS}(\mathrm{ESI})$ for $\mathrm{C}_{17} \mathrm{H}_{24} \mathrm{~B}_{10}: \mathrm{m} / \mathrm{z}=336.85[\mathrm{M}+4 \mathrm{H}]^{+} .{ }^{1} \mathrm{H} \mathrm{NMR}\left(\mathrm{CDCl}_{3}\right.$, ppm), $\delta=7.64-6.69\left(\mathrm{~m}, 9 \mathrm{H}, \mathrm{C}_{6} \underline{\mathrm{H}}_{5}\right.$ and $\left.\mathrm{C}_{6} \underline{\mathrm{H}}_{4}\right), 6.62\left(\mathrm{~m}, 1 \mathrm{H}, \underline{\mathrm{C}} \underline{\mathrm{H}}=\mathrm{CH}_{2}\right), 5.67-5.15$ (q, $2 \mathrm{H}$, $\left.\mathrm{CH}=\mathrm{C}_{2} 2\right), 3.03\left(\mathrm{~s}, 2 \mathrm{H}, \underline{\mathrm{C}}_{2}{ }^{-} \mathrm{C}_{6} \mathrm{H}_{4}\right), 2.82-0.84$ (m, br, $\left.10 \mathrm{H}, \mathrm{B}_{10} \underline{\mathrm{H}}_{10}\right) .{ }^{13} \mathrm{C} \mathrm{NMR}\left(\mathrm{CDCl}_{3}\right.$, ppm), $\delta=137.10,136.18,134.67,130.51,130.87,130.82,130.23,129.06$ and 126.14 $\left(\underline{\mathrm{C}}_{6} \mathrm{H}_{5}\right.$ and $\left.\underline{\mathrm{C}}_{6} \mathrm{H}_{4}\right), 114.34$ and $114.31\left(\underline{\mathrm{C}}=\underline{\mathrm{CH}}_{2}\right), 83.71$ and $82.01\left(\underline{\mathrm{C}}_{\text {cage }}\right), 40.67\left(\underline{\mathrm{CH}}_{2^{-}}\right.$ $\left.\mathrm{C}_{6} \mathrm{H}_{4}\right) .{ }^{11} \mathrm{~B} \mathrm{NMR}\left(\mathrm{CDCl}_{3}, \mathrm{ppm}\right), \delta=-3.41\left(2 \mathrm{~B},{ }^{1} \mathrm{~J}_{\mathrm{BH}}=154 \mathrm{~Hz}\right),-9.83\left(4 \mathrm{~B},{ }^{1} \mathrm{~J}_{\mathrm{BH}}=103 \mathrm{~Hz}\right),-$ $10.33\left(4 \mathrm{~B},{ }^{1} \mathrm{~J}_{\mathrm{BH}}=207 \mathrm{~Hz}\right)$. IR ( KBr pellet, $\left.\mathrm{cm}^{-1}\right), 3039(\mathrm{w}, \mathrm{s}), 2956(\mathrm{w}, \mathrm{s}), 2926(\mathrm{~m}, \mathrm{~s})$, 2855(w, s), 2583(vs, s), 2562(vs, s), 1908(w, s), 1833(w, s), 1724(w, s), 1628(m, s), 1508(m, s), 1491(m, s), 1443(m, s), 1407(m, s), 1358(m, s), 1285(w, s), 1162(w, s), 1115(m, s), 1073(m, s), 996(m, s), 911(s, s), 830(m, s), 756(m, s), 691(s, s), 584(m, s), 492(m, s).

\subsection{Synthesis of poly(closo-1-Me-2-(4-vinylbenzyl)-1,2-closo- $\left.\mathrm{C}_{2} \mathrm{~B}_{10} \mathrm{H}_{10}\right)(3)$.}

To a solution of $0.80 \mathrm{~g}$ (2.92 mmol) of $\mathbf{1}$ in $4 \mathrm{~mL}$ of anhydrous toluene AIBN (25mg; 0.15 mmol) was added under argon. The mixture was allowed to react at $80^{\circ} \mathrm{C}$ for 5 hours with constant stirring. The reaction mixture was first poured into $400 \mathrm{~mL}$ of hexane and then cooled. The precipitated products were collected by filtration followed by washing with hexane $(2 \times 15 \mathrm{~mL})$ and dried in vacuo at $50^{\circ} \mathrm{C}$ to isolate the polymer product 3 with consistent weight ( 0.45g, yield 56.3\%). GPC analytic data: Mw 5795 Da, Mw/Mn 2.37. ${ }^{1} \mathrm{H}$ NMR $\left(\mathrm{CDCl}_{3}, \mathrm{ppm}\right), \delta=7.01-6.81$ (br, 4H, $\left.\mathrm{C}_{6} \underline{\mathrm{H}}_{4}\right), 3.37$ (br, 2H, $\left.\underline{\mathrm{C}}_{2}-\mathrm{C}_{6} \mathrm{H}_{4}\right), 2.90-$ 0.86 (m, br, $\left.16 \mathrm{H}, \mathrm{C}_{\text {cage }}-\underline{\mathrm{C}}_{3},-\underline{\mathrm{C}}^{\mathrm{H}}-\underline{\mathrm{H}}_{\underline{2}^{-}}, \mathrm{B}_{10} \underline{\mathrm{H}}_{10}\right) .{ }^{13} \mathrm{C} \mathrm{NMR}\left(\mathrm{CDCl}_{3}, \mathrm{ppm}\right), \delta=130.52-$ $127.75(\mathrm{~m})\left(\underline{\mathrm{C}}_{6} \mathrm{H}_{4}\right), 78.02$ and $75.06\left(\underline{\mathrm{C}}_{\mathrm{cage}}\right), 40.87\left(\underline{\mathrm{C}} \mathrm{H}_{2}-\mathrm{C}_{6} \mathrm{H}_{4}\right), 23.65\left(\mathrm{C}_{\text {cage }}-\underline{\mathrm{CH}}_{3}\right) .{ }^{11} \mathrm{~B}$ 
NMR $\left(\mathrm{CDCl}_{3}, \mathrm{ppm}\right), \delta=-6.13(\mathrm{br}),-10.56$ (br). IR (KBr pellet, $\left.\mathrm{cm}^{-1}\right), 3021(\mathrm{~m}, \mathrm{~s}), 2928(\mathrm{~m}$, s), 2582(vs, s), 1512 (s, s), 1443 (s, s), 1387(m, s), 1319(w, s), 1160(m, s), 1115(m, s), 1019(s, s), 950(m, s), 919(w, s), 856(m, s), 817(s, s), 729(s, s), 647(m, s), 591(m, s), $557(\mathrm{~m}, \mathrm{~s})$.

4.4 Synthesis of poly(closo-1-Ph-2-(4-vinylbenzyl)-1,2-closo- $\left.\mathrm{C}_{2} \mathrm{~B}_{10} \mathrm{H}_{10}\right)(4)$.

In a procedure identical that reported above in $4.3,1.02 \mathrm{~g}$ (yield $85.0 \%$ ) of polymer 4 was isolated from 1.20g of 2. GPC analytic data: Mw $3029 \mathrm{Da}, \mathrm{Mw} / \mathrm{Mn} 1.79 .{ }^{1} \mathrm{H}$ NMR $\left(\mathrm{CDCl}_{3}, \mathrm{ppm}\right), \delta=7.66-6.54$ (br, $9 \mathrm{H}, \mathrm{C}_{6} \underline{\mathrm{H}}_{5}$ and $\left.\mathrm{C}_{6} \underline{\mathrm{H}}_{4}\right), 2.97-0.87$ (m, br, 15H, $\mathrm{C}_{\text {cage }}-\underline{\mathrm{C}}_{2}$, $\left.-\mathrm{C} \underline{\mathrm{H}}-\underline{\mathrm{C}}_{\underline{2}^{-}}, \mathrm{B}_{10} \underline{\mathrm{H}}_{10}\right) .{ }^{13} \mathrm{C} \mathrm{NMR}\left(\mathrm{CDCl}_{3}, \mathrm{ppm}\right), \delta=131.37-127.28(\mathrm{~m})\left(\underline{\mathrm{C}}_{6} \mathrm{H}_{5}\right.$ and $\left.\underline{\mathrm{C}}_{6} \mathrm{H}_{4}\right)$, 81.60 and $82.43\left(\underline{\mathrm{C}}_{\mathrm{cage}}\right), 40.52\left(\underline{\mathrm{CH}}_{2}-\mathrm{C}_{6} \mathrm{H}_{4}\right) .{ }^{11} \mathrm{~B} \mathrm{NMR}\left(\mathrm{CDCl}_{3}, \mathrm{ppm}\right), \delta=-5.32$ (br), 11.74 (br). IR (KBr pellet, $\mathrm{cm}^{-1}$ ), 3055(m, s), 3021(m, s), 2924(s, s), 2851(w, s), 2579(vs, s), 1958(w, s), 1902(w, s), 1609(w, s), 1581(w, s), 1511(m, s), 1495(s, s), 1445(s, s), 1425(s, s), 1319(w s), 1261(w, s), 1157(w, s), 1112(w, s), 1070(m, s), 1026(w, s), 933(w, s), 881(m, s), 857(m, s), 818(m, s), 757(s, s), 729(m, s), 691(vs, s), 650(m, s), 594(m, s), 565(m, s), 492(m, s).

4.5 Ceramic coating of graphene oxide (GO) with polymer 3,4 and polystyrene to protect against oxidation.

A $60 \mathrm{mg}$ of polymer was taken into a $25 \mathrm{~mL}$ round-bottom flask and dissolved in $2.0 \mathrm{~mL}$ of dichloromethane. The GOs (60 mg) were then dipped into this solution and dried under $\mathrm{N}_{2}$. The coated GOs were subsequently heated from $10{ }^{\circ} \mathrm{C} / \mathrm{min}$ to $1000{ }^{\circ} \mathrm{C}$ in a stream of $\mathrm{N}_{2}$ gas (100 $\left.\mathrm{mL} / \mathrm{min}\right)$. Upon cooling to room temperature, the ceramic polymer coated GOs were again heated from $10^{\circ} \mathrm{C} / \mathrm{min}$ to $1000^{\circ} \mathrm{C}$ in a flow of $\mathrm{O}_{2}$ gas $(100$ $\mathrm{mL} / \mathrm{min}$ ). The TGA results are shown in Figure 2.

4.6 Synthesis of polymer 3-supported palladium catalyst $(P d N P s / 3$ and $P d$ NPs/Polystyrene). 
This catalyst was prepared according to a literature method with a slight modification [32]. Accordingly, $80 \mathrm{mg}$ of $\mathbf{3}, 8 \mathrm{mg}$ of $\mathrm{PdAc}_{2}, 0.12 \mathrm{~g}$ of phenylboronic acid and $15 \mathrm{~mL}$

deionized (DI)-water were taken into a round-bottom flask equipped with magnetic stirring bar. The reaction mixture was heated to $80{ }^{\circ} \mathrm{C}$ for 1.5 hours. The aqueous layer was removed by decantation. The Pd-supported polymer 3 was washed with hexane $(5 \mathrm{x}$ $10 \mathrm{~mL})$ and water $(5 \times 15 \mathrm{~mL})$ followed by in vacuo drying at $50{ }^{\circ} \mathrm{C}$. The isolated catalyst composite was subjected to analysis by TEM, XPS and ICP.

\subsection{Procedures of catalytic oxidation of glycerol.}

A $25 \mathrm{~mL}$ round-bottom flask was equipped with magnetic stirring bar in which $0.10 \mathrm{~g}$ of glycerol (1.34 mmol), $0.05 \mathrm{~g}(0.02 \mathrm{mmol} \mathrm{Pd})$ of 3 and $0.33 \mathrm{~g}(1.43 \mathrm{mmol})$ of trichloroisocyanuric acid were added and then made the suspension of the mixture in 6 $\mathrm{mL}$ of acetonitrile. This reaction mixture was stirred at room temperature for 24 hours and then evaporated to dryness. The obtained crude product was purified by flash chromatography $\left(\mathrm{SiO}_{2}\right)$ eluting with $\mathrm{Et}_{2} \mathrm{O} /$ acetone $(\mathrm{v} / \mathrm{v}=3 / 2)$ to give dihydroxyacetone in $52 \%$ yield as the known product as identified by ${ }^{1} \mathrm{H}$ and ${ }^{13} \mathrm{CNMR}$ spectra that are consistent with the literature data. A same procedure was used to test Pd NPs/polystyrene to produce DHA in $27 \%$ yield.

\section{Acknowledgment}

We thank the Institute of Chemical and Engineering Sciences (ICES/12-4B4A01), Agency for Science, Technology and Research, Singapore, and Singapore-MIT Alliance for Research and Technology Innovation Centre (NG120510ENG(IGN)) for financial support. We also thank Ms Wang Zhan at Institute of Chemical and Engineering Sciences, Agency for Science, Technology and Research, Singapore for XPS analysis. NSH thanks the support from the National Science Foundation (Grant \#CHE-0906179) and Northern Illinois University for the Board of Trustees Professorship. 


\section{References}

[1] T.M. Keller, D.Y. Son, in: J.C. Salamone, (Eds.), Polymeric Materials Encyclopedia, CRC Press, New York, 1996, pp. 3262-3269.

[2] T.M. Keller, D.Y. Son, US Patent 5932335A, 1999.

[3] T.M. Keller, M.K. Kolel-Veetil, US Patent 7705100B2, 2010.

[4] M. Patel, A.C. Swain, Polym. Degrad. Stab. 83 (2004) 539-545.

[5] K. Kokado, Y. Tokoro, Y. Chujo, Macromolecules 42 (2009) 2925-2930.

[6] J.J. Peterson, M. Werre, Y.C. Simon, E.B. Coughlin, K.R. Carter, Macromolecules 42 (2009) 8594-8598.

[7] Y.-S. Bae, A.M. Spokoyny, O.K. Farha, R.Q. Snurr, J.T. Hupp, C.A. Mirkin, Chem. Commun. 46 (2010) 3478-3480.

[8] K. Kokado, M. Tominaga, Y. Chujo, Macromol. Rapid Commun. 31 (2010) 13891394.

[9] M. Tominaga, Y. Morisaki, Y. Chujo, Macromol. Rapid Commun. 34 (2013) 13571362.

[10] C. Wang, Y. Zhou, F. Huang, L. Du, React. Funct. Polym. 71 (2011) 899-904.

[11] E.G. Cansu-Ergun, A. Cihaner, J. Electroanal. Chem. 707 (2013) 78-84.

[12] E.G. Cansu-Ergun, A. Cihaner, Mater. Chem. Phys. 143 (2013) 387-392.

[13] A.B. Olejniczak, R. Kierzek, E. Wickstrom, Z.J. Lesnikowski, J. Organomet. Chem. 747 (2013) 201-210.

[14] F.L. Pasquale, R. James, R. Welch, E. Echeverria, P.A. Dowben, J.A. Kelber, ECS Trans. 53 (2013) 303-310.

[15] X.-Q. Li, C.-H. Wang, M.-Y. Zhang, H.-Y. Zou, N.-N. Ma, Y.-Q. Qiu, J. Organomet. Chem. 749 (2014) 327-334.

[16] M. Tominaga, Y. Morisaki, H. Naito, Y. Chujo, Polym. J. 46 (2014) 740-744. [17] A.S. Abd-El-Aziz, C.E. Carraher, C.U. Pittman, M. Zeldin, Boron-Containing Polymers, John Wiley \& Sons, New Jersey, 2007.

[18] N.S. Hosmane, J.A. Maguire, Y. Zhu, Boron and Gadolinium Neutron Capture Therapy for Cancer Treatment, World Scientific Pub Co Inc., New Jersey, 2011. 
[19] L. Liang, A. Rapakousiou, L. Salmon, J. Ruiz, D. Astruc , B.P. Dash, R. Satapathy, J.W. Sawicki, N.S. Hosmane, Eur. J. Inorg. Chem. 20 (2011) 3043-3049.

[20] H.C. Kolb, M.G. Finn, K.B. Sharpless, Angew. Chem. Int. Ed. 40 (2001) 2004-2021.

[21] B.C. Brodie, Philos. Trans. R. Soc. Lond. 149 (1859) 249-259.

[22] S. Sandoval, N. Kumar, A. Sundaresan, C.N. R. Rao, A. Fuertes, G. Tobias, Chem.

A Eur. J. 20 (2014) 11999-12003.

[23] N. Miyaura, A. Suzuki, Chem. Rev. 95 (1995) 2457-2483.

[24] M. Moreno-Manas, R. Pleixats, Acc. Chem. Res. 36 (2003) 638-643.

[25] A. Fihri, M. Bouhrara, B. Nekoueishahraki, J.-M. Basset, V. Polshettiwar, Chem.

Soc. Rev. 40 (2011) 5181-5203.

[26] A.B. Oh, V.R. Vangala, C.S. Chen, L.P. Stubs, N.S. Hosmane, Y. Zhu, Dalton Trans. 43 (2014) 5014-5020 .

[27] Y. Zhu, N.S. Hosmane, Coord. Chem. Rev. 293-294 (2015) 357-367.

[28] Y. Zhu, C. Li, M. Sudarmadji, H.M. Ng, A.B. Oh, J.A. Maguire, N.S. Hosmane, Chemistry OPEN, 1 (2012) 67-70.

[29] Dihydroxyacetone, http://marketpublishers.com. 2012.

[30] T. Mallat, A. Baiker, Chem. Rev. 104 (2004) 3037-3058.

[31] M. Besson, P. Gallezot, Catal. Today 57 (2000) 127-141.

[32] A. Ohtaka, T. Teratani, R. Fujii, K. Ikeshita, T. Kawashima, K. Tatsumi, O.

Shimomura, R. Nomura, J. Org. Chem. 76 (2011) 4052-4060.

[33] Y. Zhu, C. Li, A.B. Oh, S. Meriska, A. Chen, T.T. Dang, M.S. Abdual, Dalton Trans. 40 (2011) 9320-9325.

[34] Y. Zhu, E. Widjaja, L.P.S. Shirley, Z. Wang, K. Carpenter, J.A. Maguire, N.S.

Hosmane, M.F. Hawthorne, J. Am. Chem. Soc. 129 (2007) 6507-6512.

[35] Y. Zhu, C.P. Ship, A. Emi, Z. Su, Monalisa, R.A. Kemp, Adv. Synth. Catal. 349 (2007) 1917-1922.

[36] Y. Zhu, C. Koh, T.P. Ang, A. Emi, M. Winata, K.J. Loo, N.S. Hosmane, J.A. Maguire, Inorg. Chem. 47 (2008) 5756-5761.

[37] J.F. Moulder, W.F. Stickle, P.E. Sobol, K.D. Bomben, Handbook of X-ray Photoelectron Spectroscopy, Physical Electronics Inc. Eden Prairie, 1995.

[38] U. Tilstam, H. Weinmann, Org. Proc. Res. Develop. 6 (2002) 384-393. 
[39] H. Veisi, R. Gholbedaghi, J. Malakootikhah, A. Sedrpoushan, B. Maleki, D.

Kordestani, J. Heterocyclic Chem. 47 (2010) 1398-1405.

[40] D. Liang, S. Cui, J. Gao, J. Wang, P. Chen, Z. Hou, Chinese. J. Catal. 32 (2011) 1831-1837.

[41] S.E. Davis, M.S. Ide, R.J. Davis, Green Chem. 15 (2013) 17-45.

[42] W.L.F. Armarego, D.D. Perrin, Purification of laboratory chemicals, fourth ed., Butterworth-Heinemann, Woburn, 2000.

[43] F.-U. Albert, J.-P. E. Jose, T. Francesc, V. Clara, S. Reijo, P.-I. Ezequiel, N. Rosario, Chem. A Eur. J. 18 (2012) 544-553.

\title{
For Graphical Table of Contents
}

\section{Direct Synthesis of Carboranylpolystyrene and Their Applications for Oxidation Resistance of Graphene Oxides and Catalyst Support}

\author{
Zhu Yinghuai, ${ }^{\mathrm{a}, *}$ Zhao Wenguang, ${ }^{\mathrm{a}}$ Narayan S. Hosmane, ${ }^{\mathrm{b}}$ \\ ${ }^{a}$ Institute of Chemical and Engineering Sciences (ICES), 1 Pesek Road, Jurong Island, \\ Singapore 627833 \\ Tel+6567963801, Fax +6563166184,_E-mail: zhu_yinghuai@ices.a-star.edu.sg \\ ${ }^{b}$ Department of Chemistry and Biochemistry, Northern Illinois University, DeKalb, \\ Illinois 60115-2862, USA,
}




\section{Graphical abstract}

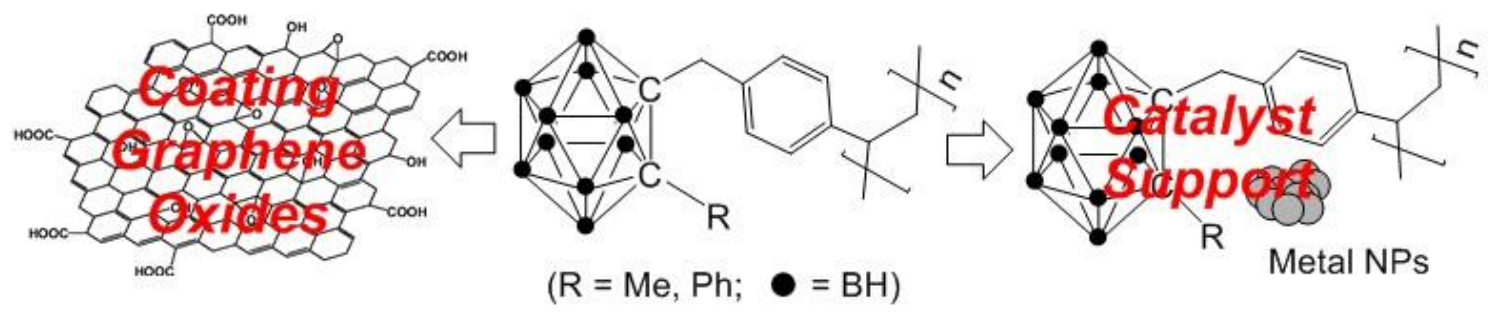

